\title{
A new biological approach in generating an irritable bowel syndrome rat model - focusing on depression in sucrose splash test and body weight change
}

\author{
RADU LEFTER ${ }^{1}$, ALIN CIOBICA ${ }^{1,2,3}$, DANIEL TIMOFTE ${ }^{4}$, DANIELA ABABEI ${ }^{4}$, ROMEO \\ DOBRIN $^{4 *}$, ANDREI LUCA ${ }^{5}$, ANCA TRIFAN ${ }^{4}$, CAROL STANCIU $^{1}$, CATALIN SFARTI ${ }^{4}$ \\ ${ }^{1}$ Center of Biomedical Research, Romanian Academy, Iasi, B-dul Carol I, no 8, Romania \\ ${ }^{2}$ Department of Research, Faculty of Biology, Alexandru Ioan Cuza University, B-dul Carol I, no 11, \\ Iasi, Romania \\ ${ }^{3}$ Academy of Romanian Scientists, Splaiul Independentei nr. 54, sector 5, 050094 Bucuresti, Romania \\ 4"Grigore T. Popa" University of Medicine and Pharmacy, 16, Universitatii Street, 700115, Iasi, Romania \\ ${ }^{5}$ Advanced Center for Research and Development in Experimental Medicine (CEMEX), UMF Grigore \\ T. Popa, Hospital of Pneumology Iasi, Str. Dr. Cihac 30, 700115 Iasi, Romania
}

\begin{abstract}
Irritable bowel syndrome (IBS) is a digestive tract functional disorder, without anatomical or structural problems, manifesting through stool abnormalities, diarrhea or constipation or both forms alternating between them over time, accompanied by abdominal pain, bloating or flatulence. These symptoms contribute not only to poor digestive absorption, disturbed intestinal motility, but can alter gut microbiota, induce intestinal inflammation through immunity mediators, and negatively impact the psychology of the person. The literature concerning animal models of IBS encompasses numerous studies based on unpredictabile chronic mild stressors applied on rodents, rats. Generally, the stress paradigms consist in exposing the animals to a series of randomly alternating micro-stressors. A key aspect when applying the low intensity stress factors is to maximize their degree of unpredictability by a randomized order, as well as the period of exposure which may last from 2 to 16 weeks. Considering the time and resource-demanding procedures for establishing such IBS stress models, we were interested in developing a reliable and effective model that would result also in the emotional depressive changes accompanying the gastrointestinal disturbances. Thus, our approach was to combine water avoidance stress, an equally reliable acute and chronic stressor, as a constantly repeated factor, with randomized unpredictable mild stressors. Thus, this is a new approach and a new combination that we presumed to be efficient even if applied for a shorter period of one week. Our results are suggesting that the current protocol of 1-week-long multiple heterotypic combination with homotypic chronic stress can be effective to replicate the behavioral manifestations similar to IBS symptoms and the accompanying depression-like features. We would presume this would be more efficient if applied for longer time, although in the present case it did work, even if applied for a shorter period of one week.
\end{abstract}

Keywords Model; irritable bowel syndrome; rat; depression; sucrose splash test; body weight change.

To cite this article: LEFTER R, CIOBICA A, TIMOFTE D, ABABEI D, DOBRIN R, LUCA A, TRIFAN A, STANCIU C, SFARTI C. A new biological approach in generating an irritable bowel syndrome rat model - focusing on depression in sucrose splash test and body weight change. Rom Biotechnol Lett. 2020; 25(3): 1554-1562. DOI: 10.25083/rbl/25.3/1554.1562

*Corresponding author: ROMEO DOBRIN, "Grigore T. Popa" University of Medicine and Pharmacy, 16, Universitatii Street, 700115, Iasi, Romania

E-mail: romeodobrin2002@gmail.com 


\section{Introduction}

Irritable bowel syndrome (IBS) is a digestive tract functional disorder, without anatomical or structural problems, manifesting through stool abnormalities, diarrhea or constipation or both forms alternating between them over time, accompanied by abdominal pain, bloating or flatulence. These symptoms contribute not only to poor digestive absorption, disturbed intestinal motility, but can alter gut microbiota, induce intestinal inflammation through immunity mediators, and negatively impact the psychology of the person (P. PORTINCASA \& al [1], M.M. RAHMAN \& al [2], Y. ENDO \& al [3]).

Currently, the global prevalence of IBS is estimated to be as high as $11.2 \%$, with an increasing trend in countries becoming more westernized, and is more common in urban as compared to rural communities (P. PORTINCASA \& al [1], M.M. RAHMAN \& al [2], Y. ENDO \& al [3]).

The pathophysiology of IBS, a complex and not yet clearly understood interaction between disrupted immune and central and enteric nervous systems (A.H. KATSANOS $\&$ al [4]), could be the result of a large number of factors including psychological stress, food intolerance or allergy, intestinal immune disruption and/or inflammation, intestinal disbyiosis, genetic transmission, abuse and early life related-events (H.Y. QIN \& al [5]). Lately, psychological and psychiatric stress is increasingly recognized as a paramount factor in the development of IBS, by altering the gut-brain interaction through hormonal imbalance resulted from the abnormal functioning of the hypothalamicpituitary-adrenal (HPA) axis and enteric sympathetic autonomous nervous system in stressful conditions (L. CHANG \& al [6], P.C. KONTUREK \& al [7]).

Also, the higher prevalence of IBS in the large cities, as compared to villages is speculated to be the result of the greater psychological stress characteristic for urban lifestyle. Also, IBS is more common in females and people of working age which are more vulnerable/exposed to stress factors (M.M. RAHMAN \& al [2], M. CORSETTI and P. WHORWELL [8], Y.T. LEE \& al [9]).

People with IBS are reported to frequently experience behavioral comorbidities, and up to $80 \%$ IBS patients suffer from anxiety and depression (M.G.VANNUCCHI and S. EVANGELISTA [10]), which further complicates the treatment of the disorder. Currently, there is no single cure for IBS, instead a tailored approach based on the predominant symptom is applied to reduce the impact on patients quality of life (QoL) (B.E. LACY \& al [11]), that has to consider the psychological problems of IBS, depression and anxiety, which are of course in causal relationship with GI symptoms (M. FADGYASSTANCULETE \& al [12]).

In order to understand the mechanisms involved in the IBS pathohysiology, and identifying therapeutic options, animal models based on psychosocial stress exposure have been developed that replicate partly IBS main symptomatology to offer face and predictive validity. Thus, a review from 2015 of stress-induced experimental IBS models, (R.D. MOLONEY \& al [13]) offers a comprehensive detailed description of the different types of animal models in this area.

Strictly referring to psychological stress as a triggering factor for the development of IBS-type phenotype in rodents, this can be applied either during early-life in the form of neonatal maternal separation or during adulthood through either acute or chronic stress (R.D. MOLONEY \& al [13]). While the maternal separation model has been shown to be a valid model of IBS pathophysiology when animals are allowed to reach maturity (S.M. O'MAHONY \& al [14] cited by R.D. MOLONEY \& al [13]), the animal models of adult stress-induced IBS, which are the focus of the current paper, will be further detailed. One approach for modeling stress in adult rodents is by using acute stress factors, such as restraint stress and water avoidance stress (WAS) (A. MULAK \& al [15]). This latter paradigm consists in placing the animal on a small platform in the middle of a water-filled basin B. BONAZ and Y. TACHÉ [16] cited by S.M. O'MAHONY \& al [14]). Thus, immobilization through either partial restraining taping of the upper forelimbs and thoracic trunk after light anesthetics (H. EUTAMENE \& al [17]), or by using plastic restrainers that closely fit to the animal (A. PONFERRADA \& al [18], S. MOZAFFARI \& al [19]), is also largely used to induce intense psychological stress. A critical role in these acute stress paradigms is played by the period of time, which, if passing over a certain threshold value can lead to habituation (R.D. MOLONEY \& al [13]). These aspects are indicating that a longer duration of over $2 \mathrm{~h}$ is susceptible to induce a certain degree of adaptation and change the behavioral output.

Thus, some authors report (A. PONFERRADA \& al [18]) that while a 6 hours acute immobilization stress (either for 1 day - acute or for 5 days - subchronic) results in stress-induced colonic inflammation and dysfunction, on the other side, a prolonged period of 10 days trend to normalize the increased inflammatory parameters.

The second approach employing chronic stressors, which are applied in a repeated but intermittent manner, is procedurally closer to mimicking the daily exposure to human psychosocial stress (A. MULAK \& al [15]). The cumulative effect obtained through repeatability of stress factors with subacute intensity is a key factor to induce visceral pain (R.D. MOLONEY \& al [13]) - thus in rats submitted daily to $1-\mathrm{h}$ WAS paradigm for 10 consecutive days, visceral hyperalgesia and enhanced fecal pellet excretion persisted for at least a month (S. BRADESI \& al [20]).

Yet, sustained exposure to a homotypic chronic stress exposure, (such as WAS, loud noises, or contention) is reported to end in a potential habituation and thus diminuation of intestinal hypersensitivity, through an incrementally decrease of HPA axis hormones over the successive days of exposure (J.A. BABB \& al [21], A. MULAK \& al [15]).

As a consequence, heterotypic stress factors of different natures and in alternating combinations and various duration exposure have been employed with positive results in mimicking IBS and comorbidities symptoms in animals. 
The literature concerning animal models of IBS encompasses numerous studies based on unpredictabile chronic mild stressors (UCMS) applied on rodents, rats (L. ZHANG \& al [22], J. SANTOS \& al [23], M. OCHI \& al [24], C.M. O'MAHONY \& al [25], M. TÕNISSAAR $\&$ al [26]) or mice (M. NOLLET \& al [27], R.K. FAROOQ $\&$ al [28], Y.S. MINEUR \& al [29], S. MONTEIRO \& al [30]). Generally, the stress paradigms consist in exposing the animals to a series of randomly alternating microstressors, such as overnight illumination or white noise during the dark phase, inverted light cycle, tail clamp, $45^{\circ} \mathrm{C}$ hot environment for 5 minutes, hot air stream from a hairdryer for 10 minutes, $4^{\circ} \mathrm{C}$ cold environment for 3 minutes, water deprivation for $24 \mathrm{~h}$, food deprivation for $24 \mathrm{~h}$, periods of confinement in a small cage, stroboscopic light exposure, shaking in an orbital shaker for $1 \mathrm{~h}$ at $150 \mathrm{rpm}$, tilted cage in a $45^{\circ}$ angle during $1 \mathrm{~h}$, damp sawdust as cage bedding, predator sound exposure (Y.S. MINEUR \& al [29], S. MONTEIRO \& al [30], Y.S. KIM \& al [31], R. ZHANG \& al [32]).

A key aspect when applying these low intensity stress factors is to maximize their degree of unpredictability by a randomized order, as well as the period of exposure which may last from 2 to 16 weeks (Y.S. KIM \& al [31]), which underlie many procedural variations.

In the end, the two main approaches, acute or chronic exposure, overlap, as restraint stress in plastic tubes can be one of the factors used in an efficient chronic unpredictable stress protocol lasting for 8 weeks (S. MONTEIRO \& al [30]) or less for 10 days (C.M. O'MAHONY \& al [25]), while chronic water avoidance stress daily for 5 days leads to mucosal barrier defects in rats (J. SANTOS \& al [23]).

In this respect, another recent approach is to combine the heterotypic chronic and acute stressors in a multifactorial interactional IBS relevant animal model. A 2016 study on the histological changes in enteric small intestine neurons in a rat model of IBS with diarrhea combined chronic unpredictable mild stressors consisting in seven different stressors applied for 3 weeks with 1 day acute restraint stress (S. LI \& al [33]). Another previous study also employed a similar protocol (H. LÜ \& al [34]) reporting the exacerbation of IBS symptoms, such as increased defecating granules and increased number of abdominal contractions. Moreover, decreased sucrose consumption and bodyweight were reported suggestive for installation of depressive behavior. Interestingly, no significant changes were found on defecating behavior when only chronic unpredictable mild stressors were applied or on sucrose consumption for wrap restraint stress only (H. LÜ \& al [34]).

Considering the time and resource-demanding procedures for establishing such IBS stress models, we were interested in developing a reliable and effective model that would result also in the emotional depressive changes accompanying the GI disturbances. Thus, our approach was to combine water avoidance stress, an equally reliable acute and chronic stressor, as a constantly repeated factor, with randomized unpredictable mild stressors. Thus, this is a new approach and a new combination that we presumed to be efficient even if applied for a shorter period of one week. Subsequent assessment of behavioral manifestations similar to the depressive comorbidities in IBS was carried out using the sucrose splash test.

\section{Materials and Methods}

The experiment was conducted on 12 adult female white Wistar rats weighing 200-210 g, which were kept in groups of three per cage in a controlled environment at $20^{\circ} \mathrm{C}, 55-60 \%$ relative humidity and natural light-dark cycle. The animals were habituated for one week following their arrival (from the Institute of Hygiene, Iasi, Romania) before the stress paradigm was initiated. Food and water were provided ad libitum except for two 24 hour periods when food or water deprivation stress was applied. Rats were treated in accordance with the guidelines of the animal bioethics of the Act on Animal Experimentation and Animal Health and Welfare from Romania and all procedures performed in studies involving animals were in compliance with Directive 2010/63/EU of the European Parliament and of the Council of 22 September 2010 on the protection of animals used for scientific purposes. The animal care and protocols were approved by the local committees.

\section{Experimental design}

The multifactorial heterotypic mild stress paradigm was performed after the animals were divided into two groups, the IBS stress exposed group and the control group. The IBS group was exposed daily to two sessions of stress for a period of 7 days consisting in one constant stressor used repeatedly each morning, succeeded by an additional stress factor that differed daily in order to minimize habituation. Thus, IBS group rats were submitted to water avoidance stress for one hour during the first half of the day for the entire week; the standard procedure involved placing the rat on a small platform $(8 \times 6 \mathrm{~cm})$ in the middle of a small plastic basin filled with warm water $\left(25^{\circ} \mathrm{C}\right)$ at the height level of the platform (P.C. YANG \& al [35]). Control group rats were placed on the same platform but in a waterless container for 1 hour. Within 6 hours from the WAS paradigm, the IBS group was exposed to one of six different stressors for each of the last six days of the protocol. The different stressors were (1) predator sound exposure for 5 minutes, (2) water deprivation for 24 hours, (3) imitation of an abdominal injection, (4) tilted cage in a $45^{\circ}$ angle for $12 \mathrm{~h},(5)$ painful tailpinch with a clothespin for two minutes, (6) food deprivation for 24 hours. Following the end of the $7^{\text {th }}$ day of stress exposure and a day of rest, behavioral tests were conducted between the interval 10:00 AM and 16:00 PM.

\section{Behavioral analysis - splash test}

Animals were permitted to accommodate to the testing room approximately $30 \mathrm{~min}$ before the test. The sucrose splash test was performed in the two groups of rats. The test was conducted under dim light, after both groups animals were isolated into individual cages and singly housed for 1 day prior to the test. An atomizer spray was used to splash two times a $10 \%$ sucrose solution on the dorsal coat of the rat which was quickly returned to 
the home cage. After spraying the sucrose solution, the total time spent in grooming, the latency to the first bout of groom and the number of grooms were recorded for a period of 5 minutes. A previous described protocol was used in our study (J. ZOU \& al [36]).

We also performed bodyweights measuring for the groups tested prior to exposure to stress and on the $7^{\text {th }}$ day after the completion of the stress protocol.

\section{Statistical analysis}

All results were expressed as mean \pm standard deviations (SD). Behavioral activities of rats were statistically analyzed using one way ANOVA analysis of variance. Results were regarded as significant at $\mathrm{p}<0.05$.

\section{Results}

Body weight for the two groups did not differ significantly on the first day before stress: $205 \pm 2 \mathrm{~g}$ vs. $207 \pm 3 \mathrm{~g}$. At the end of the 7 days stress protocol weight gain for the IBS group was clearly reduced when compared to the control group. The mean body weight for the IBS group was $212 \pm 3 \mathrm{~g}$ while the average body weight for the control group increased to $217 \pm 3 \mathrm{~g}(\mathrm{p}=0.322)$.

In the sucrose splash test the symptoms of depression reflected by lack of self care were assessed through three parameters regarding the grooming behavior, as mentioned previously (time spent in grooming, the latency to the first bout of groom and the number of grooms). The results presented in Figure 1 showed that rats undergoing the stress protocol had a tendency to neglect coat grooming relative to the control group. We observed a significantly decreased latency to initiate grooming (Figure $1 \mathrm{~A}, \mathrm{p}<0.04$ ), a slight not significant reduction in the total duration of grooming (Figure $1 \mathrm{~B}, \mathrm{p}<0.4$ ) and a diminution of grooming frequency (Figure $1 \mathrm{C}, \mathrm{p}>0.2$ ). These data suggest that even a one week period of combined heterotypic stress will affect self-care in stressed animals, but results should be more relevant under longer exposure period.
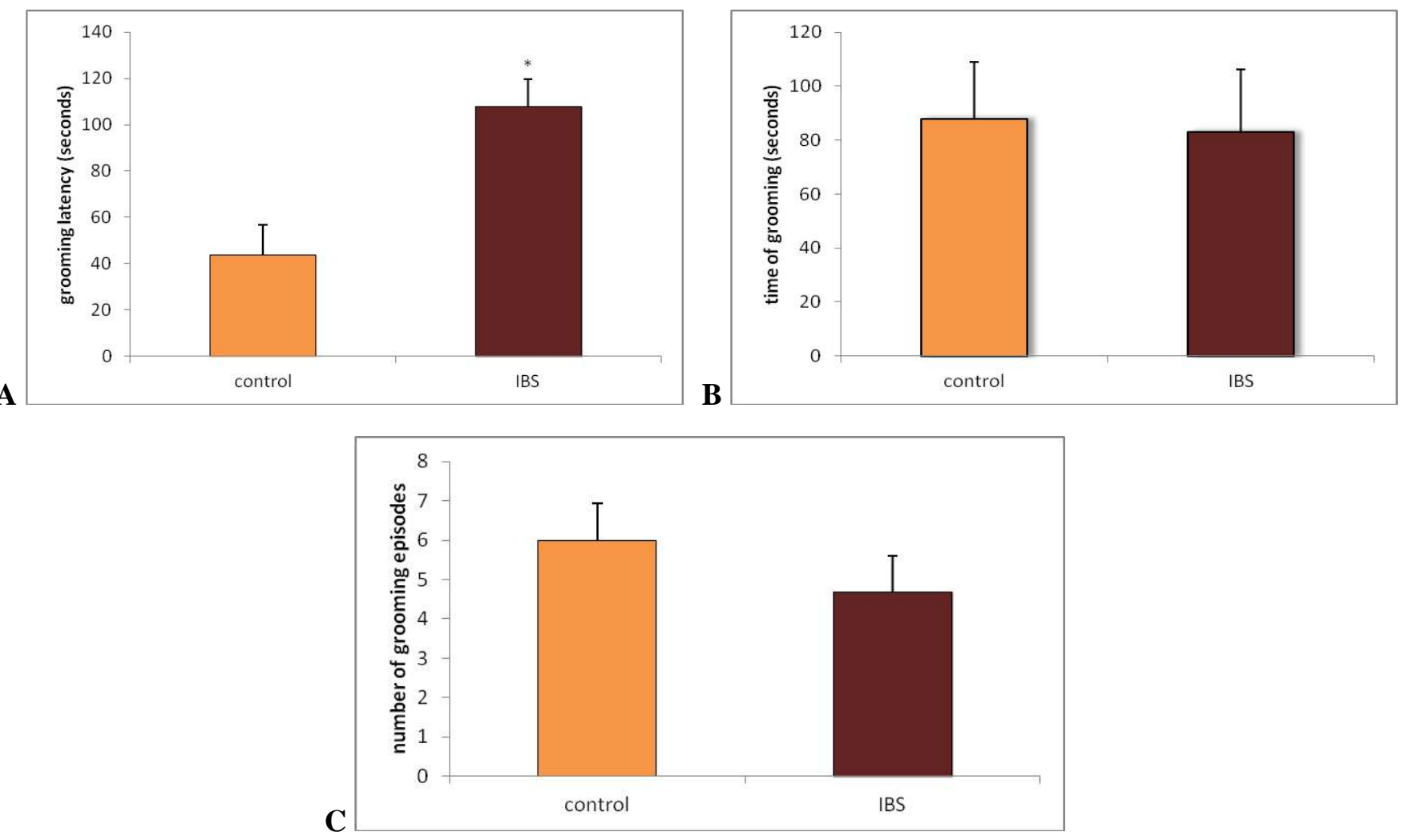

Figure 1. Irritable bowel syndrome (IBS) rats submitted to 1 week heterotypic multiple stress factors display reduced grooming behavior in the splash test following a 10\% sucrose solution spray. A: Grooming latency (seconds), ${ }^{*} \mathrm{p}<0.04$ vs control; B: Time of grooming (seconds), $\mathrm{p}<0.4$; C: Number of grooming episodes, $\mathrm{p}>0.2$.

\section{Discussion}

The aim of this study was to establish a new protocol of stress exposure for inducing IBS symptomatology and assess its reliability as a tool in replicating the depressive manifestations co-occurring with GI disturbances. The novelty of our paradigm lies in the combination between a homotypic factor equally reliable as an acute and a chronic stressor and six other unpredictable mild stressors.
We found that using this paradigm a relative short period of 7 days alters affective mood albeit results would be more relevant under longer exposure period.

Numerous studies have attempted to replicate IBS and depression in animal models either by acute or chronic stress (L. ZHANG \& al [22], C.M. O'MAHONY \& al [25], M. TÕNISSAAR \& al [26], (M. NOLLET \& al [27], R.K. FAROOQ \& al [28], Y.S. MINEUR \& al [29], S. MONTEIRO \& al [30], T. STREKALOVA and H.W. 
STEINBUSCH [37]). However, fulfilling all three main criteria for a neuropsychiatric disorder animal model, i.e. face validity, construct (or etiological) validity and pharmacological validity remains a challenge [R. LEFTER \& al [69].

Considering the complexity of the human simptomatology, focusing on inducing visceral hypersensitivity (e.g. one of the main signs of IBS) is not enough, as the emotional and cognitive manifestations must be considered. In a study assessing intestinal motility and visceral pain, as well as affective behavior, in either acute, chronic or combined stress exposed rodent model of IBS, Lü and colleagues reported that neither significant change was found on defecating behavior in the chronic unpredictable mild stress model of depression, nor on sucrose consumption in the acute wrap restraint stress model (H. LÜ \& al [34]). However, the multifactorial interactional animal model based on the chronic acute combining stress was relevant for both visceral and depressive symptoms.

Different regulative mechanisms must be involved in the pathways of either acute or chronic stress on the brain and gut innervation in IBS, yet not many studies focused on the different manifestations between chronic and acute stress in animal models. In this way, Zou and colleagues analyzed both intestinal manifestations and protein expression of the G-protein subtype in the hippocampus and the frontal cortex in two rat models of chronic and acute stress (N. ZOU \& al [38]). The abnormal function or expression of the subunits of the heterotrimeric $G$ proteins are reported by some studies to appear in the biochemical mechanism underlying lithium action and in the pathophysiology of depression (S. AVISSAR \& al [39], M.J. WILKIE \& al [40]). The Western blot analysis showed that the subtypes of brain G-protein expression were downregulated only in the chronic, but not in acute stressed rats, suggesting that chronic stress may induce more clear changes in the brain and serve as a more accurate IBS model.

Also, intestinal manifestations (motility, visceral perception, and epithelial secretion, decreased epithelial barrier) were similar in both models, but other phenotypic indicators potentially relevant for depressive symptoms, such as decreased sucrose intake and delayed weight gain appeared only in chronic stressed rats (N. ZOU \& al [38]).

In addition, an insight study on the molecular mechanisms underlying IBS visceral pain, analysed c-fos levels (a marker of activation of tissue cells) for cerebral tissue and colon by immunohistochemistry obtained from rat models of IBS induced by heterotypic chronic and respectively acute stress (R. ZHANG \& al [32]). The results showed a correlation between increased c-fos in CNS (frontal lobe, hippocampus, and cornu dorsale) and abnormal number of EC cells and 5-HT level in the colon of the IBS rats group - indicating that psychological stress might induce hyperexcitability of colon indirectly through activation of CNS - but the authors do not specify any differences between the two IBS models (R. ZHANG $\&$ al [32]).
Another study found that increased rectal mucosal enterochromaffin cell count and depression were equally important predictors of developing IBS in patients after Campylobacter infection (S.P. DUNLOP \& al [41]). The impact of acute and chronic stress in rats was also assessed in terms of metabolic response, as the expression of urinary metabolites through quantitative analytical metabonomic measurement (X. WANG \& al [42]).

There are also numerous studies demonstrating that urinary amines and metabolites are elevated biomarkers in depression and even relate to the severity degree of major depressive disorder (S.H. KOSLOW \& al [43], J.J. CHEN $\&$ al [44]). Metabonomic assessment showed that urinary metabolites expression is altered in the acute stress model in the same way as in the chronic model (with only the exception of pimelate and hippurate that changed in an opposite trend) and was validated by behavior and physiologic results (X. WANG \& al [42]).

The major challenge in modeling depression in animals is to generate not the various experimentally induced behavioral defeat or despair, a physiological depression, which ultimately is a form of adaptive involuntary defeat strategy, but the long-lasting state of pathological depression (V. KRISHNAN and E.J. NESTLER [45]). This may be the shortfall of acute stressors, in that they would not provide sufficient support/substratum for behavioral transient alterations to develop into a more human-like depressive state accompanied by persistent changes, behavioral and neurobiological. Chronic stress models however are noticed to have stronger face validity and construct validity for depression, due to the multiple disturbances resulting from environmental and psychological stressors (M. NOLLET \& al [27]). However, these chronic stress protocols require more time to be completed, as well as greater sample size, making them more expensive from multiple considerations (V. KRISHNAN and E.J. NESTLER [45]). Strekalova and Steinbusch also mention that many studies using with chronic stress as a common depression paradigm led to inconsistent behavioral results and advises testing under dimmed lighting and moderation of the stress load (T. STREKALOVA and H.W. STEINBUSCH [37]) to counter confounding factors in stressed rodents stressed such as hyperlocomotion or individual variability. Currently, according to a most recent study from 2017, the number of labs publishing CMS studies more than doubled from 81 in 2010 to 180 in 2015 , despite the difficulty of the protocols (P. WILLNER [46]).

Among the critical factors that would question the reliability of the stress protocol, individual variability within the sub-groups of the tested animals, the time and intensity of the protocol are commented to be the most important (P. WILLNER [46]). While overcoming the subgroup variability in response to stress would ultimately require a sufficient sample size, a high power of the experiment also needs a high, intense dose rate to obtain a strong response (M.F.W. FESTING [47]). 
Thus, the decline of body weight, which occurred in our study in just one week could be considered an adequate indicator of stress load (intensity), which in controlled environmental conditions could scale down inter-individual variability towards a sufficiently homogeneous response (C. GAMBARANA [48]). Regarding the total time of exposure, one interest focus of the present study was to evaluate if our minimal threshold in reducing the exposure period to only one week would allow discerning relevant depressive signs in our multiple heterotypic chronic stress model. We consider that increasing the exposure time more would benefit obtaining more robust data, but one week was sufficient to modify body weight change and significantly alter grooming latency of splash test, two parameters considered as the most relevant tests for the chronic stress rat model along with sucrose preference, coat stat score, open-field score and immobility time in force swimming test (C. HU \& al [49]).

Regarding the sex effects (e.g. - another important factor reported to influence the outcome of stress protocol (C. DALLA \& al [50]), our results validate the use of female rats as an appropriate option to observe disorders that are reportedly prevalent in women, such as IBS (C. CANAVAN \& al [51]) and depression (M.V. SCHMIDT $\&$ al [52], R.C. KESSLER [53]). Thus, a previous study reported increased incidence of depression and anxiety in female mice, following chronic mild stress exposure suggesting that, unlike males, females are more susceptible to 5-HT depletion and its mood-depressing effects (B.D. SACHS \& al [54])

Also, up to this date, the focus on targets related to specific symptoms has brought the production of drugs aimed to treat constipation or diarrhea to alternate results. This choice did not focus on the possibility to look for drugs useful for global IBS symptoms. Thus, a more integrated view on the disease seems to be desirable for now, in order to develop efficient therapies that can counteract the chronic natural history of IBS (M.G. VANNUCCHI \& al [55]).

Another consideration must be made regarding the significance of the current animal model for IBS manifestations: the characteristics of fecal elimination in mice, ressemblant to diarrhea, were assessed prior to the splash test, as part of a larger undergoing study focusing on more complex behavioristic characterization of this model and a systemic antioxidant therapeutic approach.

In fact, oxidative stress seems to exert an important role in IBS, as our group previously described the relations that might appear between IBS, some neurological deficiencies and oxidative stress (I.M BALMUS \& al [56]). Thus, there is a possible relevance of some antioxidants administration in IBS (as recent reviews are suggesting I. KHAN \& al [57]), as this could be also relevant in the light of our previous work in this area of research, where we preliminary demonstrated the role of some antioxidant plant extract in animal models of IBS (S. GUENNE \& al [58]), as well as the relevance of the oxidative stress status in most of neuropsychiatric and affective manifestations, including the depression chronicity (C. STEFANESCU $\&$ al [59], I. BALMUS \& al [60], A. CIOBICA \& al [61,
62, 64, 65, 68], O. ALEXINSCHI \& al [63], W. BILD \& al [66], R. DOBRIN \& al [67]).

In addition, we are currently working on designing some protocols regarding the relevance of Camelina sp. or other plants extracts on these neuropsychiatric manifestations and animal models, considering the previous encouraging results on this matter (F. IMBREA \& al [70, 74], P. DOBRE \& al [71], I. TONCEA \& al [72], S.M. PETRE \& al [73], M. APOSTU \& al [75], H.S. FOYET \& al [76], R. DOBRINOIU \& al [77]).

\section{Conclusions}

Our results are suggesting that the current protocol of 1-week-long multiple heterotypic combination with homotypic chronic stress can be effective to replicate the behavioral manifestations similar to IBS symptoms and the accompanying depression-like features. We would presume this would be more efficient if applied for longer time, although in the present case it did work, even if applied for a shorter period of one week.

\section{Acknowledgments}

$\mathrm{RL}$ and $\mathrm{CA}$ are supported by a research great for Young Teams offered by UEFISCDI Romania, no. PN-IIIP1-1.1-TE-2016-1210, contract no. 58 din 02/05/2018, called "Complex study regarding the interactions between oxidative stress, inflammation and neurological manifestations in the pathophysiology of irritable bowel syndrome (animal models and human patients)".

\section{References}

1. P. PORTINCASA, L. BONFRATE, O. DE BARI, A. LEMBO, S. BALLOU, Irritable bowel syndrome and diet. Gastroenterol. Rep., 5 (1), 11, 19 (2017).

2. M.M. RAHMAN, S. MAHADEVA, U.C. GHOSHAL, Epidemiological and clinical perspectives on irritable bowel syndrome in India, Bangladesh and Malaysia: A review. World. J. Gastroenterol., 7, 23 (37), 6788, 6801 (2017).

3. Y. ENDO, T. SHOJI, S. FUKUDO, Epidemiology of irritable bowel syndrome. Ann. Gastroenterol. Hellènike Gastrenterologikē Hetaireia, 28 (2), 158, 159 (2015).

4. A.H. KATSANOS, S. GIANNOPOULOS, G. TSIVGOULIS, The brain-gut axis in the pathophysiology of irritable bowel syndrome. Immuno-Gastroenterol., 1, 23, 26 (2012).

5. H.Y. QIN, C.W. CHENG, X.D. TANG, Z.X. BIAN, Impact of psychological stress on irritable bowel syndrome. World J. Gastroenterol., 20(39), 14126, 14131 (2014).

6. L. CHANG, S. SUNDARESH, J.ELLIOTT, P.A. ANTON, P. BALDI, A. LICUDINE, M. MAYER, T. VUONG, M. HIRANO, B.D. NALIBOFF, V.Z. AMEEN, E.A. MAYER, Dysregulation of the hypothalamic-pituitary-adrenal (HPA) axis in irritable bowel syndrome. Neurogastroenterol. Motil.: The Official 
Journal of the European Gastrointestinal Motility Society, 21(2), 149, 159 (2009).

7. P.C. KONTUREK, T. BRZOZOWSKI, S.J. KONTUREK, Stress and the gut: pathophysiology, clinical consequences, diagnostic approach and treatment options. J Physiol. Pharmacol., 62(6), 591, 599 (2011).

8. M. CORSETTI, P. WHORWELL, The global impact of IBS: time to think about IBS-specific models of care? Therap. Adv. Gastroenterol., 10(9), 727, 736 (2017).

9. Y.T. LEE, L.Y. HU, C.C. SHEN, M.W. HUANG, S.J. TSAI, A.C. YANG, C.K. HU, C.L. PERNG, Y.S. HUANG, J.H. HUNG, Risk of Psychiatric Disorders following Irritable Bowel Syndrome: A Nationwide Population-Based Cohort Study. PLoS One, 29, 10(7): e0133283 (2015).

10. M.G.VANNUCCHI, S. EVANGELISTA, Experimental Models of Irritable Bowel Syndrome and the Role of the Enteric Neurotransmission. J Clin Med., 3, 7(1). pii: E4 (2018).

11. B.E. LACY, K.WEISER, R. DE LEE, The Treatment of Irritable Bowel Syndrome. Therap. Adv. Gastroenterol., 2(4), 221, 238 (2009).

12. M. FADGYAS-STANCULETE, A.M. BUGA, A. POPA-WAGNER, D.L. DUMITRASCU, The relationship between irritable bowel syndrome and psychiatric disorders: from molecular changes to clinical manifestations. J Mol Psychiatry, 2(1), 4 (2014).

13. R.D. MOLONEY, S.M. O'MAHONY, T.G. DINAN, J.F. CRYAN, Stress-induced visceral pain: toward animal models of irritable-bowel syndrome and associated comorbidities. Front Psychiatry, 16, 6, 15. (2015).

14. S.M. O'MAHONY, A.M. COELHO, P. FITZGERALD, K. LEE, W.WINCHESTER, T.G. DINAN, J.F. CRYAN, The effects of gabapentin in two animal models of co-morbid anxiety and visceral hypersensitivity. Eur J Pharmacol., 667, 169, 174 (2011).

15. A. MULAK, M. LARAUCHE, Y. TACHÉ, Psychological Stress Induces Visceral Analgesic or Hyperalgesic Response in Rodents: A Role of Preconditions. Front Gastrointest Res., 30, 106, 114 (2012).

16. B. BONAZ, Y. TACHÉ, Water-avoidance stressinduced $\mathrm{c}$-fos expression in the rat brain and stimulation of fecal output: role of corticotropinreleasing factor. Brain Res. 28, 641(1), 21, 28 (1994).

17. H. EUTAMENE, V. THEODOROU, J. FIORAMONTI, L. BUENO, Acute stress modulates the histamine content of mast cells in the gastrointestinal tract through interleukin-1 and corticotropin-releasing factor release in rats. J Physiol., 15, 553(Pt 3), 959-966 (2003).

18. A. PONFERRADA, J.R. CASO, L. ALOU, A. COLÓN, D. SEVILlANO, M.A. MORO, I. LIZASOAIN, P. MENCHÉN, M.L. GÓMEZ-LUS, P. LORENZO, E. COS, J.C. LEZA, L. MENCHÉN. The role of PPARgamma on restoration of colonic homeostasis after experimental stress-induced inflammation and dysfunction. Gastroenterol., 132(5), 1791, 1803 (2007).

19. S. MOZAFFARI, H. ESMAILY, R. RAHIMI, M. BAEERI, Y. SANEI, A. ASADI-SHAHMIRZADI, M.H. SALEHI-SURMAGHI, M. ABDOLLAHI, Effects of Hypericum perforatum extract on rat irritable bowel syndrome. Pharmacogn Mag., 7(27), 213, 223 (2011)

20. S. BRADESI, I. SCHWETZ, H.S. ENNES, C.M. LAMY, G. OHNING, M.FANSELOW, C. POTHOULAKIS, J.A. MCROBERTS, E.A. MAYER, Repeated exposure to water avoidance stress in rats: a new model for sustained visceral hyperalgesia. Am J Physiol Gastrointest Liver Physiol., 289(1), G42-53 (2005).

21. J.A. BABB, C.V. MASINI, H.E. DAY, S. CAMPEAU, Habituation of hypothalamic-pituitary-adrenocortical axis hormones to repeated homotypic stress and subsequent heterotypic stressor exposure in male and female rats. Stress, 17 (3), 224, 234 (2014).

22. L. ZHANG, J. LUO, M. ZHANG, W. YAO, X. MA, S.Y. YU, Effects of curcumin on chronic, unpredictable, mild, stress-induced depressive-like behaviour and structural plasticity in the lateral amygdala, Int. J. Neuropsychopharmacol., 17 (5), 793, 806 (2014).

23. J. SANTOS, M. BENJAMIN, P.C. YANG, T. PRIOR, M.H. PERDUE, Chronic stress impairs rat growth and jejunal epithelial barrier function: role of mast cells. Am. J. Physiol. Gastrointest Liver Physiol., 278 (6), 847, 454 (2000).

24. M. OCHI, K. TOMINAGA, F. TANAKA, T. TANIGAWA, M. SHIBA, T. WATANABE, Y. FUJIWARA, N. OSHITANI, K. HIGUCHI, T. ARAKAWA, Effect of chronic stress on gastric emptying and plasma ghrelin levels in rats. Life Sci., 9, 82(15-16), 862, 868 (2008).

25. C.M. O'MAHONY, G. CLARKE, S. GIBNEY, T.G. DINAN, J.F. CRYAN, Strain differences in the neurochemical response to chronic restraint stress in the rat: relevance to depression. Pharmacol. Biochem. Behav., 97(4), 690, 699 (2011).

26. M. TÕNISSAAR, L. HERM, M. ELLER, K. KÕIV, A. RINKEN, J. HARRO, Rats with high or low sociability are differently affected by chronic variable stress. Neurosci., 9, 152(4), 867, 876 (2008).

27. M. NOLLET, A.M. LE GUISQUET, C. BELZUNG, Models of depression: unpredictable chronic mild stress in mice. Curr Protoc Pharmacol., 5, 5.65., doi: 10.1002/0471141755.ph0565s61, (2013).

28. R.K. FAROOQ, E. ISINGRINI, A. TANTI, A.M. LE GUISQUET, N. ARLICOT, F. MINIER, S. LEMAN, S. CHALON, C. BELZUNG, V.CAMUS, Is unpredictable chronic mild stress (UCMS) a reliable model to study depression-induced neuroinflammation? Behav. Brain. Res., 16, 231(1), 130, 137 (2012).

29. Y.S. MINEUR, C. BELZUNG, W.E. CRUSIO, Effects of unpredictable chronic mild stress on anxiety and depression-like behavior in mice. Behav Brain Res., 75(1), 43, 50. (2006). 
30. S. MONTEIRO, S. ROQUE, D. DE SÁ-CALÇADA, N. SOUSA, M. CORREIA-NEVES, J.J. CERQUEIRA, An efficient chronic unpredictable stress protocol to induce stress-related responses in $\mathrm{C} 57 \mathrm{BL} / 6$ mice. Front. Psychiatry, 2, 6, 6, doi: 10.3389/fpsyt.2015. 00006 (2015).

31. Y.S. KIM, M.Y. LEE, C.S. CHOI, Y.W. SOHN, B.R. PARK, M.G. CHOI, Y.H. NAH, S.C. CHOI, The effect of chronic variable stress on bowel habit and adrenal function in rats. J. Gastroenterol. Hepatol., 23(12), 1840, 1846, (2008).

32. R. ZHANG, N. ZOU, J. LI, H. LV, J. WEI, X.C. FANG, J.M. QIAN, Elevated expression of c-fos in central nervous system correlates with visceral hypersensitivity in irritable bowel syndrome (IBS): a new target for IBS treatment. Int. J. Colorectal Dis., 26(8), 1035, 1044 (2011)

33. S. LI, G. FEI, X. FANG, X. YANG, X. SUN, J. QIAN, J.D. WOOD, M. KE, Changes in Enteric Neurons of Small Intestine in a Rat Model of Irritable Bowel Syndrome with Diarrhea. J Neurogastroenterol. Motil., 30, 22(2), 310, 320 (2016).

34. H. LÜ, J.M. QIAN, G.L. JIN, D.F. ZHOU, Y.C. SHEN, The establishment of an animal model of gut-brain interaction in irritable bowel syndrome for the evaluation of visceral sensation, motility and psychological behavior. Zhonghua Nei Ke Za Zhi, 48 (12), 1035, 1039 (2009).

35. P.C. YANG, J. JURY, J.D. SÖDERHOLM, P.M. SHERMAN, D.M. MCKAY, M.H. PERDUE, Chronic psychological stress in rats induces intestinal sensitization to luminal antigens. Am J Pathol., 168(1), 104, 114 (2006).

36. J. ZOU, W. WANG, Y.W. PAN, G.M. ABEL, D.R. STORM, Z. XIA, Conditional Inhibition of Adult Neurogenesis by Inducible and Targeted Deletion of ERK5 MAP Kinase Is Not Associated with Anxiety/ Depression-Like Behaviors. eNeuro., 16, 2(2). pii: ENEURO.0014-14.2015 (2015).

37. T. STREKALOVA, H.W. STEINBUSCH, Measuring behavior in mice with chronic stress depression paradigm. Prog Neuropsychopharmacol Biol Psychiatry., 17, 34(2), 348, 361 (2010).

38. N. ZOU, H. LV, J. LI, N. YANG, H. XUE, J. ZHU, J. QIAN, Changes in brain $\mathrm{G}$ proteins and colonic sympathetic neural signaling in chronic-acute combined stress rat model of irritable bowel syndrome (IBS). Transl Res., 152(6), 283, 289 (2008).

39. S. AVISSAR, Y. NECHAMKIN, G. ROITMAN, G. SCHREIBER, Reduced $G$ protein functions and immunoreactive levels in mononuclear leukocytes of patients with depression. Am. J. Psychiatry, 154 (2), 211, 217 (1997).

40. M.J. WILKIE, D. SMITH, I.C. REID, R.K. DAY, K. MATTHEWS, C.R. WOLF, D. BLACKWOOD, G. SMITH, A splice site polymorphism in the G-protein beta subunit influences antidepressant efficacy in depression. Pharmacogenet. Genomics, 17 (3), 207, 215 (2007).
41. S.P. DUNLOP, D. JENKINS, K.R. NEAL, R.C. SPILLER, Relative importance of enterochromaffin cell hyperplasia, anxiety, and depression in postinfectious IBS. Gastroenterol., 125, 1651, 1659 (2003).

42. X. WANG, T. ZHAO, Y. QIU, M. SU, T. JIANG, M. ZHOU, A. ZHAO, W. JIA, Metabonomics approach to understanding acute and chronic stress in rat models. J. Proteome Res., 8(5), 2511, 2518 (2009).

43. S.H. KOSLOW, J.W. MAAS, C.L. BOWDEN, J.M. DAVIS, I. HANIN, J. JAVAID, CSF and urinary biogenic amines and metabolites in depression and mania. A controlled, univariate analysis. Arch. Gen. Psychiatry, 40(9), 999, 1010 (1983).

44. J.J. CHEN, C.J. ZHOU, P. ZHENG, K. CHENG, H.Y. WANG, J. LI, L. ZENG, P. XIE, Differential urinary metabolites related with the severity of major depressive disorder. Behav. Brain Res. 14(332), 280, 287 (2017).

45. V. KRISHNAN, E.J. NESTLER, Animal Models of Depression: Molecular Perspectives. Curr. Top. Behav. Neurosci., 7, 121,147 (2011).

46. P. WILLNER, Reliability of the chronic mild stress model of depression: A user survey. Neurobiol Stress., 6, 68, 77 (2017).

47. M.F.W.FESTING, How to Reduce the Number of Animals Used in Research by Improving Experimental Design and Statistics ANZCCART C/ - The Univ of Adelaide, Protocol Based Fact Sheets, Fact Sheet T10, https://www.adelaide.edu.au/ANZCCART/docs/factsheets/T10_HowtoReducetheNumberFactSheet.pdf (2011)

48. C. GAMBARANA, Experimental Protocols for the Study of Stress in Animals and Humans, S. YEHUDA, D.I. MOSTOFSKY, eds., Humana Press Inc., Totowa, NJ, 2005, pp. 21-35.

49. C. HU, Y. LUO, H. WANG, S. KUANG, G. LIANG, Y. YANG, S. MAI, J. YANG, Re-evaluation of the interrelationships among the behavioral tests in rats exposed to chronic unpredictable mild stress. PLoS One., 20, 12(9), e0185129 (2017).

50. C. DALLA, P.M. PITYCHOUTIS, N. KOKRAS, Z. PAPADOPOULOU-DAIFOTI, Sex differences in response to stress and expression of depressive-like behaviours in the rat. Curr Top Behav Neurosci., 8, 97, 118 (2011).

51. C. CANAVAN, J. WEST, T. CARD, The epidemiology of irritable bowel syndrome. Clin Epidemiol., 6, 7, 80 (2014).

52. M.V. SCHMIDT, S.H. SCHARF, C. LIEBL, D. HARBICH, B. MAYER, F. HOLSBOER, M.B. MÜLLER, A novel chronic social stress paradigm in female mice. Horm Behav., 57 (4-5), 415, 420 (2010).

53. R.C. KESSLER, Epidemiology of women and depression. J Affect Disord., 74(1), 5, 13 (2003).

54. B.D. SACHS, J.R. NI, M. CARON, Sex differences in response to chronic mild stress and congenital serotonin deficiency. Psychoneuroendocrinol., 40, 123, 129 (2014). 
55. M.G. VANNUCCHI, S. EVANGELISTA, Experimental models of irritable bowel syndrome and the role of the enteric neurotransmission. J. Clin Med. 7, E4 (2018).

56. I.M BALMUS, A. CIOBICA, A. TRIFAN, C. STANCIU, Irritable bowel syndrome, neurological deficiencies and oxidative stress: is there a relationship?, Psychiatria Danub. (2018), in press.

57. I. KHAN, S. SAMSON, A. GROVER, Antioxidant Supplements and Gastrointestinal Diseases: A Critical Appraisal. Medical Principles and Pract. 26, 201-217 (2017).

58. S. GUENNE, R. LEFTER, A. CIOBICA, A. TRIFAN, M. COMPAORE, A. HILOU, M. KIENDREBEOGO, C. STANCIU, Chrysanthellum americanum extract administration is reducing depressive manifestations in an animal model of Irritable Bowel Syndrome. $1^{\text {st }}$ International Congress on Evidence Based Mental Health, Corfu, Greece, May $26^{\text {th }}-29^{\text {th }}, 78-79$ (2016).

59. C. STEFANESCU, A. CIOBICA, The relevance of oxidative stress status in first episode and recurrent depression. J Affect Disord. 143, 34-8 (2012).

60. I. BALMUS, A. CIOBICA, I. ANTIOCH, R. DOBRIN, D. TIMOFTE, Oxidative Stress Implications in the Affective Disorders: Main Biomarkers, Animal Models Relevance, Genetic Perspectives, and Antioxidant Approaches. Oxid Med Cell Longev. 3975101 (2016).

61. A. CIOBICA, L. HRITCU, V. NASTASA, M. PADURARIU, W. BILD, Inhibition of central angiotensin converting enzyme exerts anxiolytic effects by decreasing brain oxidative stress. Journal of Medical Biochem. 30, 109-114 (2011).

62. A. CIOBICA, L. HRITCU, M. PADURARIU, R. DOBRIN, V. BILD, Effects of serotonin depletion on behavior and neuronal oxidative stress status in rat: relevance for anxiety and affective disorders. Adv Med Sci. 55(2), 289-296 (2010).

63. O. ALEXINSCHI, R. CHIRITA, A. CIOBICA, M. PADURARIU, R. DOBRIN, R. PREPELITA, I.L. SERBAN, V. CHIRITA, The relevance of oxidative stress status in one week and one month alcohol abstinent patients, J Med Biochem. 33(3), 284-290 (2014).

64. A. CIOBICA, V. BILD, L. HRITCU, M. PADURARIU, W. BILD, Effects of angiotensin II receptor antagonists on anxiety and some oxidative stress markers in rat. Central European Journal of Med. 6(3), 331-340 (2011).

65. A. CIOBICA, M. PADURARIU, I. DOBRIN, C. STEFANESCU, R. DOBRIN, Oxidative stress in schizophrenia - focusing on the main markers. Psychiatr Danub. 23(3), 237-45 (2011).

66. W. BILD, A. CIOBICA, Angiotensin-(1-7) central administration induces anxiolytic-like effects in elevated plus maze and decreased oxidative stress in the amygdale. Journal of Affective Disord. 145(2), 165-71 (2013).
67. R. DOBRIN, I. DOBRIN, C. STEFANESCU, A. CIOBICA, I.L. SERBAN, E ANTON, A Direct Correlation Between The Scores Of PANSS/ AIMS Scales And Some Oxidative Stress Markers In Treated Schizophrenic Patients. Archives of Biological Sciences Belgr. 66(4), 559-1565 (2014).

68. A. CIOBICA, M. PADURARIU, L. HRITCU, The effects of short-term nicotine administration on behavioral and oxidative stress deficiencies induced by a rat model of Parkinson's disease. Psychiatr Danub. 24(2), 194-205 (2012).

69. R. LEFTER, D. COJOCARU, A. CIOBICA, I.M. PAULET, I.L. SERBAN, E. ANTON, Aspects of animal models for the major neuropsychiatric disorders. Archives of Biological Sciences Belgr. 66(3), 105-1115 (2014).

70. F. IMBREA, S. JURCOANE, H.V. HALMAJAN, M. DUDA, L. BOTOS, Camelina sativa: A new source of vegetal oils. Rom Biotech Lett. 16 (3), 6263-6270 (2011).

71. P. DOBRE, S. JURCOANE, F. MATEI, C. STELICA, N. FARCAS, A.C. MORARU, Camelina sativa as a double crop using the minimal tillage system. Rom Biotech Lett. 19 (2), 9190-9195 (2014).

72. I. TONCEA, D. NECSERIU, T. PRISECARU, L.N. BALINT, M.I. GHILVACS, M. POPA, The seed's and oil composition of Camelia - first romanian cultivar of camelina (Camelina sativa, L. Crantz). Rom Biotech Lett. 18(5), 8594- 8602 (2013).

73. S.M. PETRE, A. MORARU, P. DOBRE, S. JURCOANE, Research on Camelina sativa wintering, by genotype and fertilizer doses used, in the pedoclimatical conditions from the south of Romania. Rom Biotech Lett. 19(6), 9964- 9973 (2014).

74. F. IMBREA, S. JURCOANE, G. POP, I. M. IMBREA, L. BOTOS, F. CRISTA, L. SMULEAC, In search of plant sources for serine protease inhibitors: I. Detection of serine protease inhibitors in callus cultures induced from somatic explants of flax (Linum usitatissimum L.). Rom Biotech Lett. 22(4), 12762-12766 (2017).

75. M. APOSTU, G. TANTARU, M. VIERIU, A.D. PANAINTE, N. BIBIRE, L. AGOROAEI, Evaluation of in Vitro Reducing Effect of Several Vegetable Extracts on the Digestive Bioavailability of Heavy Metals. Rev Chim. 68(4): 683-686 (2017).

76. H.S. FOYET, H.H. ABAÏSSOU, E. WADO, E.A. ACHA, C. ALIN C, Emilia coccinae (SIMS) G Extract improves memory impairment, cholinergic dysfunction, and oxidative stress damage in scopolaminetreated rats. BMC Complement Altern Med. 23(15), 333 (2015).

77. R. DOBRINOIU, S. JURCOANE, S. DANAILAGUIDEA, M. MORARU, M. DUMBRAVA, The impact of new technological approaches upon establishing production components and yield randament in Carthamus tinctorium L. culture. Rom Biotech Lett. 16 (2), 6125-6134 (2011). 